\title{
Effect of Time-Area Percent Curves in Development of Clark Model Unit Hydrograph
}

\author{
S. Rajkumar, S. Mohanarajah and H.M. Junaid
}

\begin{abstract}
This paper describes the effect of time - area percent curves in the development of Clark model unit hydrograph. This hydrology modelling study refers to event base modeling in order to derive the unit hydrograph from Clark instantaneous unit hydrograph. For this study, Kelani river basin up to Hanwella gauging site has been represented as the study area. Hydrologic Modelling System software developed by HEC, USA (HEC-HMS) has been used for the development of unit hydrographs under the Clark UH transform model. Three numbers of different time - area percent curves of Kelani river basin have been asynchronously used as input to the Clark UH transform model in order to obtain different simulations. The parameters, time of concentration $T_{c}$ and storage coefficient $R$ values were calibrated and validated individually, against the various percent curves for the future analysis. The best suitable percent curve is identified based on the goodness of fit criteria, Nash-Sutcliffe Efficiency (NSE) with high accuracy. For the Loss model, initial and constant rate method was preferred. In the Meteorological Model, Gaged weight was considered for rainfall analysis. For the Transform Model or Direct Runoff Model, Clark UH is considered. For the Base flo $\mathrm{W}$ model Recession, constant option was preferred. The Calibration (manual and automatic) was conducted for the storm events of May 2017, December 2014 and November 2012.Validation was conducted for the storm event of June 2014. The calibration and validation process was conducted for analyzing the hourly rainfall-runoff data for storm events observed during the monsoon seasons of the relevant years. The conclusions of the study would be very much applicable for the key personnel for taking structural and non-structural measures against the flood menace which is a frequent challenge over the study area concerned.
\end{abstract}

Keywords: Percent Curve, Thiessen Polygon, HEC-HMS

\section{Introduction}

\subsection{General}

The fundamental theory of derivation of UH is very much useful in hydrological modeling studies. The direct runoff modeling also referred to as transform modeling - plays a significant role in the modeling studies. The program HEC-HMS used in this study, conceptually facilitates two options for the Transform models. These models are (i) Empirical models also known as system theoretical models and (ii) Conceptual models. The Clark UH Transform model, employed in this study- also falls under the empirical models. These empirical approaches follow the traditional UH theories[1].

Clark (1945) introduced his model and improved the concept and understanding of physical characteristics which influence runoff and flood producing capacity of streams[2]. Clark's method of deriving synthetic unit hydrograph(SUH) deals with instantaneous unit hydrograph (IUH).

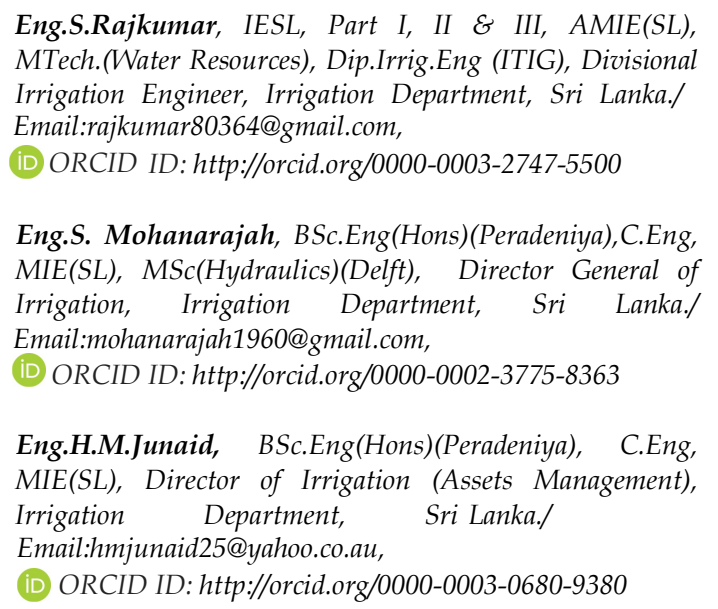


IUH mathematically conveys the excess precipitation into runoff to the outlet through two components such as (i) a translation hydrograph and (ii) attenuation [3][4]. The translation flow is the function of time-area relations whereas attenuation is the effect of channel storage [5].

In this concept, the channel storage is treated as a linear reservoir storage for routing process. The Clark IUH can be derived by routing the unit excess rainfall with the conversion from time-area diagram of the watershed through a single linear reservoir [6].

The time-area histogram is developed in order to translate water volume in each area to the outlet considered, using corresponding time of travel of its translation. Development of the time-area relation of a basin is a complicated task unless software is used. Preparation of isochrone maps is essential to derive time histograms. Isochrone defines that the imaginary line connecting equivalent time of travels to the outlet of a particular watershed. In this study, the isochrone map for the Kelani river basin up to Hanwella outlet is prepared in three different approaches. The first approach is synthetic time area relation. Other two approaches are carried out using two interpolation techniques such as Inverse distance weighted (IDW) and Kriging, which are available in ArcGIS software.

The application of synthetic time -area relation is described in the technical manual of HECHMS [7]. The interpolation techniques in ArcGIS obligatorily require certain inputs to produce isochrone maps. The inputs are the coordinates of remote points which are available with known time of travels to the outlets considered. Those remote points and their time of travels are computed with the application of HEC-GeoHMS which an extension package of ArcGIS is and is used to import the basin characteristics from ArcGIS to HEC-HMS.

The internal process of the derivation of Clark IUH has been programmed in the Clark $\mathrm{UH}$ transform model available in HEC-HMS [8]. The time-area relation is to be represented in the form of cumulative time - area percent curve under Clark UH model available in HEC-HMS. HEC-HMS is a set of mathematical models to simulate the precipitation - runoff routing processes of dendritic watershed systems [9]. The software tool Aeronautical Reconnaissance Coverage Geographical Informatics System (ArcGIS) is simultaneously employed with such modeling tasks nowadays [10]. GIS application enables to provide a digital representation of watershed characterization used in hydrological modeling in order to carryout flood assessment studies [11]. Flood estimation studies nowadays mainly deal with hydrological modelling software which are being updated with latest algorithms of computer application language [12].

\subsection{Study Area}

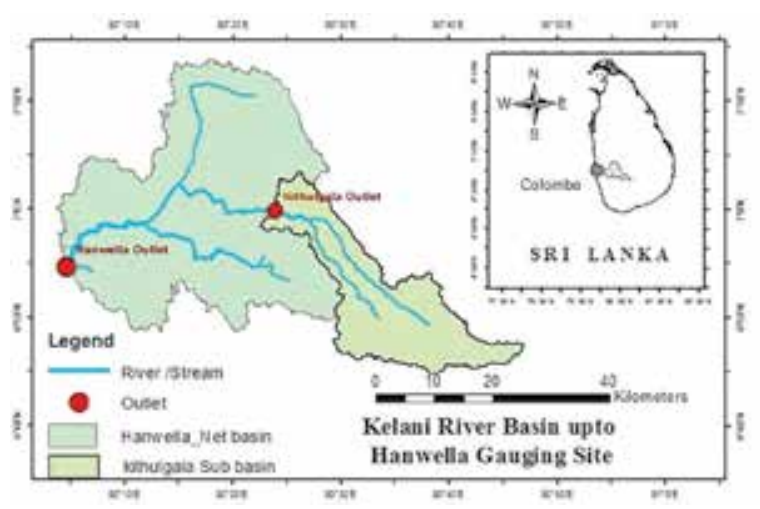

Figure 1 - Study Area

Kalani river basin up to Hanwella outlet, having an area of 1836 square kilometers, has been chosen for this study (Figure 1). Kelani river basin is located within the northern latitudes from $6^{\circ} 45^{\prime}$ to $7^{\circ} 14^{\prime}$ and eastern longitudes from $80^{\circ} 04^{\prime}$ to $80^{\circ} 47^{\prime}$. The river basin lies in the districts of Colombo, Gampaha, Kegalle, Ratnapura and Nuwara-Eliya. Kelaniriver is the fourth largest river in Sri Lanka.

\section{Materials and Methods}

2.1 Data Availability and Data Processing The Digital Elevation Model (DEM) of $30 \mathrm{~m}$ resolution, which is freely available, was downloaded from the United States Geological Survey (USGS) website. DEM is the fundamental need of the HEC-Geo HMS tool to create the basin model. The soil data and land use - land cover maps are obtained to from a recent past study[8].

Meteorological data (hourly rainfall) for selected extreme flood events and hourly 
Hydrological data (discharge \& water level for selected extreme flood events) at six (06) gauging stations were obtained. These stations (shown in Figure 3) are Hanwella, Norwood, Deraniyagala, Kithulgala, Holombuwa and Glencourse located in the upper basin This data was obtained from the Department of Irrigation, Colombo, Sri Lanka for model calibration and validation. The event-based model calibration and validation is carried out by considering the extremely heavy rainfall events that occurred in the recent past (Table 1). To obtain the average rainfall of the basin, the Theisen polygon is processed in ArcGIS to obtain the gauge weights.

Table 1 - Flood Events Employed for Calibration and Validation.

\begin{tabular}{cc}
\hline Flood Events & Duration in days \\
\hline May 2017 & 16 \\
\hline December 2014 & 8 \\
\hline June 2014 & 8 \\
\hline November 2012 & 12 \\
\hline
\end{tabular}

\subsection{Application of ArcGIS and Preparation of Isochrone Maps}

Application of ArcGIS is mainly involved in the spatial data processing. Watershed delineation, Digital elevation map, Theisen polygon map and Isochrone maps using different interpolation techniques are outputs of the application of ArcGIS. Accurate raw DEM is essential to feed as input to prepare a watershed and digital elevation map. Rain gauge stations and their coordinates are required as input to produce the 'Theisen' polygon map. Remote points with known time of travels and the coordinates of those points are required for preparing isochrone maps of the basin using different interpolation techniques.

To prepare the isochronal map of the basin, some points, located on the Kelani river and its tributaries in the basin are identified using HECGeoHMS. The time of travels from all these points up to Hanwella gauging site are required to be estimated. In this regard, the time of travels of all the segments, obtained from considering the two consecutive points on the streams, are taken to be directly proportional to $\mathrm{L} / \sqrt{\mathrm{s}}$. This can be demonstrated by the Manning's equation as follows

$$
\mathrm{V}=\frac{\mathrm{R}^{\frac{2}{3}} \times \mathrm{S}^{1 / 2}}{\mathrm{n}}
$$

where $\mathrm{V}$ is the average velocity of the stream in $\mathrm{m} / \mathrm{s}$ at the end of the segment.

$\mathrm{R}$ is the hydraulic radius in $\mathrm{m}$ for the stream cross section at the end of the segment,
$S$ is average longitudinal slope of the channel segment and $n$ is the Manning's Roughness Coefficient of the Chanel segment at its end.

However, the Manning's equation can be rearranged in terms of stream length $\mathrm{L}$ and time of travel $t_{c}$ considering the end channel as a wide rectangular channel and $\mathrm{V}=\mathrm{L} / \mathrm{t}_{\mathrm{c}}$. Then the equation may be written as:

$$
\mathrm{t}_{\mathrm{c} .}=\mathrm{C} . \mathrm{L} / \sqrt{\mathrm{S}}
$$

where $C=\left(R^{2 / 3}\right) / n$. The value of $C$ s is considered to be constant.

The time of travel from the farthest point of the catchment to the outlet of the basin along the longest stream was considered as the time of concentration of the catchment $\left(\mathrm{T}_{\mathrm{c}}\right)$. The time of travel for $i^{\text {th }}$ segment is computed as $t_{c i}=C L_{i} / \sqrt{S_{i}}$. Subsequently, the time of travel for each river is computed as $\mathrm{C}$ times the sum of $\mathrm{L} / \sqrt{\mathrm{S}}$ for each individual segment of the river and the tributaries i.e. $[\mathrm{C}(\mathrm{L} 1 / \sqrt{\mathrm{S}} 1+\mathrm{L} 2 / \sqrt{\mathrm{S}} 2+\mathrm{L} 3 / \sqrt{\mathrm{S}} 3+\ldots \ldots \ldots+$ $\mathrm{Ln} / \sqrt{\mathrm{S}} \mathrm{n})]$, where $\mathrm{n}$ is number of segments for any river reach. The max value of $C \sum(\mathrm{L} / \sqrt{S})$ is found from all the river reaches. It is equal to time of concentration $\left(\mathrm{T}_{\mathrm{c}}\right)$. Thus

$$
\mathrm{Tc}=\mathrm{C} \sum(\mathrm{L} / \sqrt{\mathrm{S}})
$$

An initial estimate of $T_{c}$ is obtained from the excess rainfall hyetograph and direct surface runoff hydrograph for a storm event. Tc is the time from the end of excess rainfall to point of inflection on the recession limb of the direct surface runoff. 
Now Eq. (3) is used to obtain the value of Constant $\mathrm{C}$ knowing the value $\mathrm{T}_{\mathrm{c}}$ and $\sum(\mathrm{L} / \sqrt{\mathrm{S}})$ for the longest flow path.

To prepare the isochronal maps, the following interpolation methods, available in the ArcGIS, are used:

- Inverse Distance Weighted (IDW) Interpolation

- Kriging Interpolation

The Time-Area curve is developed using the above methods. It is presented in the form of a Time-Area Histogram as well as cumulative TimeArea Percent curves. In addition to this, a synthetic Time-Area curve is developed within the HEC-HMS program, considering the diamond shape of the basin. It provides an option for using the inbuilt time area curve in place of user defined time area curve. The HEC-HMS software has a predefined typical time-area relationship which has been built in the program as shown in Eq. (4) by considering the shape of the basin as diamond shape in order to make the time - area relationship smooth.

$$
\frac{\mathrm{At}}{\mathrm{A}}=\left\{\begin{array}{cc}
1.414\left(\frac{\mathrm{t}}{\mathrm{Tc}}\right) & \text { for } \mathrm{t} \leq \frac{\mathrm{Tc}}{2} \\
1-1.414\left(\frac{\mathrm{t}}{\mathrm{Tc}}\right) & \text { for } \mathrm{t} \geq \frac{\mathrm{Tc}}{2}
\end{array}\right\}
$$

where At = Cumulative watershed area contributing at time $\mathrm{t}$; $\mathrm{A}=$ total watershed area; and $\mathrm{T}_{\mathrm{c}}=$ time of concentration of the watershed.

2.3

Application of HEC-GeoHMS and HECHMS

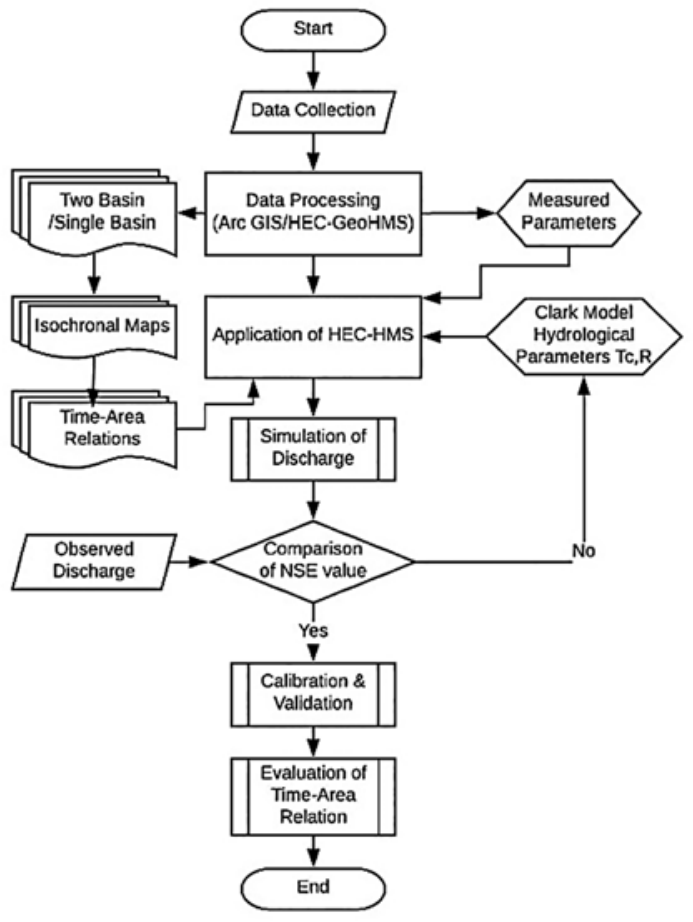

Figure 2 - Flow Diagram for Methodology
HEC-GeoHMS is Geospatial Hydrological Modelling System, the extended supplementary application tool of ArcGIS and used to develop basin model and its characteristics from the raw digital elevation model (DEM) in a convenient manner. Basin Model is created by HEC-GeoHMS with two sub basins and used for the calibration and verification process.

The required basin characteristics such as longest flow path, river lengths, upstream \& downstream elevations and slopes of each river segments are obtained via this HEC-GeoHMS application process [13]. The element network of the basin which represented in HEC-HMS desktop is also performed by HEC-GeoHMS.

Subsequently, the developed basin model representing element network in HEC-GeoHMS is imported to HEC-HMS for further application. HEC-HMS is the simulation software developed to simulate all types hydrological processes of watershed [9]. The software is user friendly and available as an open source. It is designed by USACE with updated versions and treats manner. The entire modeling process mainly is executed by the software HEC-GeoHMS and HEC-HMS. Figure 2 illustrates the calibration and validation process of the modelling of this study.

Meteorological Model is created by selecting gage weight option available in this HEC-HMS model.

Gage weights, estimated from Thiessen polygon method, are used for this option. There are three options available in the HEC-HMS program for the computation of baseflow. Those are:

- Constant, Monthly - varying value

- Exponential recession model

- Linear-reservoir accounting model

In this study, the exponential-recession model and constant monthly varying value model are used to separate the base flow from the flood hydrographs resulting from different storm events in order to estimate the direct surface runoff hydrographs for the Hanwella net basin and Kithulgala sub basin respectively. The initial parameter values of the above two base flow models are obtained from the available observed flood hydrographs data. These initial parameter values are required to set up the HEC-HMS model for validation and calibration [1]. 
There are numerous runoff volume models also known as loss models, available in HEC-HMS modelling.

- Initial and Constant Rate Loss Model

- Deficit and Constant Rate Loss Model

- SCS - CN Loss Model

- Green and Ampt Loss Model

- SMA Loss Model

In the application of loss model in this work, the method Initial loss \& constant rate is used for both the sub basins. This method includes two parameters, initial loss $\left(I_{a}\right)$ and constant loss rate. These parameters are highly dependent on the physical properties of the river basin soil, land use, and antecedent moisture conditions.

The HEC-HMS program consists of various transform models as given below;

- Clark UH Model;

- SCS UH Model;

- Snyder UH Model;

- Mod. Clark Model; and

- Kinematic Wave Model.

In this study, the Clark UH transform model is used for the event-based rainfall-runoff modelling. The basic concept of the Clark UH model defines that the temporary storage of water over the basin (in the soil and channels) plays an important role in the transformation of rainfall excess to direct runoff. The linear reservoir relationship is generally used to show the effects of this temporary storage. The linear reservoir relationship may be represented by the following continuity equation:

$$
\frac{\mathrm{dS}}{\mathrm{dt}}=\mathrm{I}_{\mathrm{t}}-\mathrm{O}_{\mathrm{t}}
$$

where $\mathrm{dS} / \mathrm{dt}$ is the time rate of change of water in storage at time $\mathrm{t}$; It is the average inflow to the storage at time $t$, and $\mathrm{O}_{t}$ is the out flow from storage at time $t$.

Storage and outflow at time $t$ have the relationship with the linear reservoir model as follows.

$$
S_{t}=R \cdot O_{t}
$$

where $\mathrm{R}$ is a constant linear reservoir parameter (storage coefficient). From the above equations (5) and (6), the following relationships are yielded.

$$
\mathrm{O}_{\mathrm{t}}=\mathrm{C}_{\mathrm{A}} \mathrm{I}_{\mathrm{t}}+\mathrm{C}_{\mathrm{B}} \mathrm{O}_{\mathrm{t}-1}
$$

where $C_{A}$ and $C_{B}$ are routing coefficients. The computation of these coefficients is given below:

$$
\mathrm{C}_{\mathrm{A}}=\frac{\Delta \mathrm{t}}{\mathrm{R}+0.5 \Delta \mathrm{t}}
$$

$\mathrm{C}_{\mathrm{B}}=1-\mathrm{C}_{\mathrm{A}}$

The average outflow is given by

$$
\overline{\mathrm{O}_{\mathrm{t}}}=\frac{\mathrm{O}_{\mathrm{t}}+\mathrm{O}_{\mathrm{t}-1}}{2}
$$

Since the cumulated effects of all basin storage are represented in this Clark UH model, the reservoir may be considered to be located conceptually at the outlet considered. In addition to this lumped model of storage, the Clark UH model computes the time required for water to move outlet from the basin. It carries this out with a linear channel model, in which water is routed from remote points to the outlet with delay (translation) but without attenuation. This delay is implicitly related to time and area, so called time-area histogram. This specifies the basin area contributing flow at the outlet as a function of time. If the area is multiplied by the unit depth of excess rainfall and divided by the time step $\Delta t$, the result is inflow, $\mathrm{I}_{\mathrm{t}}$, to the outlet (linear reservoir).

However, application of Clark UH model in HECHMS requires the parameters described below:

- Time of concentration $\mathrm{T}_{\mathrm{c}}$;

- Storage Coefficient, R; and

- Properties of Time-area histogram or Time-Area Percent Curve of the basin

The $T_{c}$ and the storage coefficient $R$ were estimated from sensitivity analysis to employ as initial parameter values. The time - area percent curves are developed using various methods as described under Section 2.2.

\subsection{Sensitivity Analysis}

Sensitivity analyses are carried out using the three simulations of Clark UH model with the threedifferent time-area percent curves in order to define the range of initial parameters to be considered during the optimization. In this regard, NSE values are computed for different sets of parameter values for different percent curves. As the Clark UH model is a two parameter model, NSE contours are drawn considering different values of one parameter $\left(T_{c}\right)$ values on $x$ axis and correspondingly the other parameter(R) values on y-axis. Such contours are helpful to identify the band of the maximum NSE value. Finally, the initial parameters values are decided considering them within this band. The initial parameter value is chosen corresponding to the maximum NSE value. The sensitivity analysis is carried out for the four flood events individually. 
Nash-Sutcliffe Efficiency Coefficient (NSE)

$$
=1-\left[\frac{\sum_{\mathrm{i}=0}^{\mathrm{n}}(\mathrm{Qobs}(\mathrm{i})-\mathrm{Qcom}(\mathrm{i}))^{2}}{\sum_{\mathrm{i}=0}^{\mathrm{n}}(\mathrm{Qobs}(\mathrm{i})-\overline{\mathrm{Q}})^{2}}\right]
$$

where Qobs, Qcom, and $\bar{Q}$ are the observed, simulated and observed mean discharge over the $\mathrm{n}$ hours respectively. The most optimal value of NSE is 1.

Volume deviation $\left(\mathrm{D}_{\mathrm{V}}\right)$

$$
\mathrm{Dv}=\left|\frac{(\text { Vobs }- \text { Vcom })}{\text { Vobs }}\right| \times 100 \%
$$

where Vobs and Vcom are the observed and simulated volume of runoff over the $n$ hours respectively. The most optimal value of $D_{V}$ is 0 (zero).

Percent error in peak $(Z)$

$$
=\left|\frac{\text { Qobs(peak) }- \text { Qcom(peak) }}{\text { Qobs (peak) }}\right| \times 100 \%
$$

where Qobs (peak) and Qcom (peak)are the observed and simulated peak discharge of runoff over the $\mathrm{n}$ hours respectively. The most optimal value of $Z$ is 0 (zero).

NSE has been reported as the best performance criterion of simulation [14]. However, in addition to the NSE, percent error in peak, percent error in time to peak, percent error in discharge volume of each direct runoff model were compared individually for each of the flood events considered for calibration and validation[8].

\subsection{Model Calibration and Validation using Three Different Time-Area Relations}

Calibration of transform models is carried out using the automatic calibration (optimization) option available in HEC-HMS. However, for the optimization runs, the initial parameter values of the models are required to be estimated. In this regard, sensitivity analysis is carried out for estimating the parameters. The calibrations of the model are carried out based on the various goodness of fit measures derived from the observed and simulated hydrographs in HECHMS program. Based on these measures, the optimized parameters of the Clark UH model, are selected. Calibration is carried out for a selected number of events and the representative parameters are derived taking the average of the optimized parameters obtained for each event considered for the calibration. The representative parameters of the Clark UH model under the three-different consideration of time area percent curves are used in HEC-HMS for their validation over the selected storm events not considered for calibration.

\section{Analysis and Results}

\subsection{Data Processing}

Thiessen polygon map is developed using ArcGIS as shown in Figure 3. Hourly rainfall values were available for storm events at 6 rain-gauge stations located within the basin. The locations of these six rain gauge stations are considered to prepare this map. Gauge weights for the two sub basins are computed by using Thiessen polygon method. From Figure 3, it is observed that the Norwood rain-gauge station has the least Thiessen Gauge Weight for the Hanwella net basin compared to the other rain gauge stations. The Thiessen Gauge Weights for the six rain gauge stations influence the Hanwella net basin whereas only two Theisen gauge weights namely Kithulgala and Norwood, influence the Kithulgala sub basin. The corresponding Thiessen Gauge weights are considered as input to the Meteorological Model for HEC-HMS program to individually compute the average hourly rainfall over the sub basins for all four storm events using Thiessen Polygon Method.

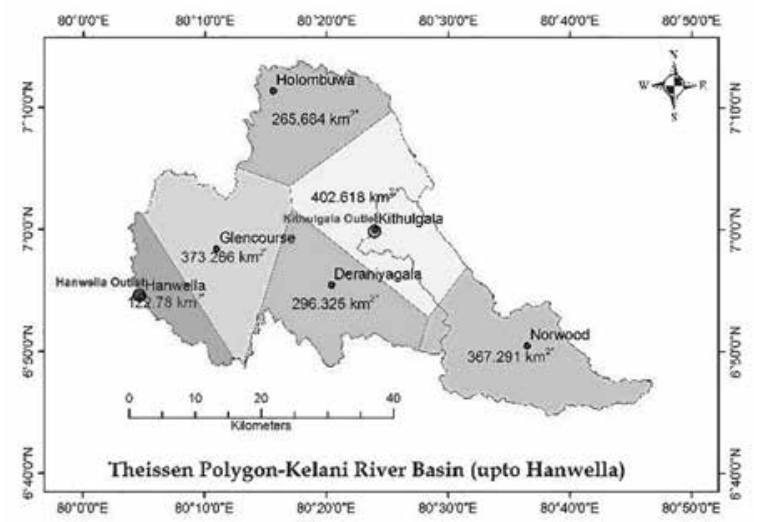

Figure 3 - Thiessen Polygon

The isochrone map is prepared following the methodology under Section 2.2. The longest flow path and river reaches are identified using HECGeoHMS software. Figure 4. shows the longest low path and river reaches. The physical characteristics of the known river segments are obtained from the attribute table of Figure 4. Max value of $\sum(\mathrm{L} / \sqrt{\mathrm{S}})$ is found from that attribute table. Thus, the $\mathrm{L} / \sqrt{\mathrm{S}}$ for the longest flow path from the catchment characteristics is estimated as $1,426,460.89 \mathrm{~m}$. Then value for constant $\mathrm{C}$ is determined from Eq. (3). 


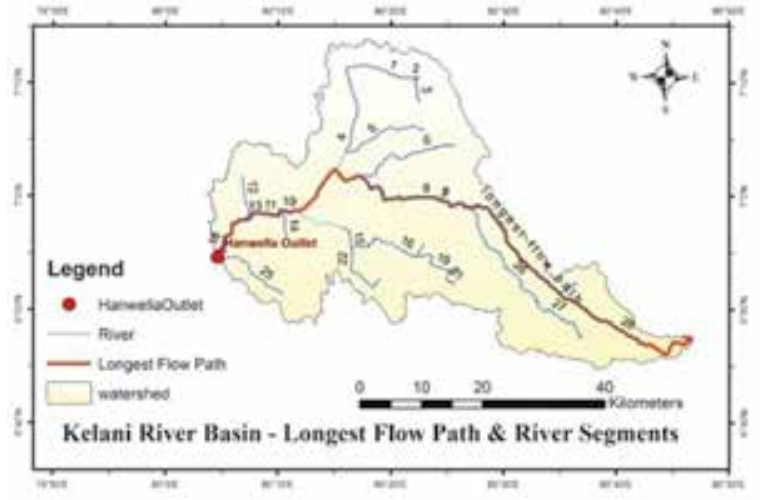

Figure 4 - Longest Flow Path and River Reaches

Max value of $\Sigma(\mathbf{L} / \sqrt{\mathbf{S}})$ is found from the attribute table in Figure 4. Thus, the $L / \sqrt{\mathbf{S}}$ for the longest flow path from the catchment characteristics is estimated as $1,426,460.89$. Then, the value for constant $\mathrm{C}$ is determined from $\mathrm{Eq}$. (3).

Inverse Distance Weighted (IDW) Interpolation Method (using ArcGIS): These isochrones are drawn using inverse distance weighted (IDW) interpolation technique of ArcGIS which helps to interpolate a raster surface from points with its known time of travel as shown in Figure 5.

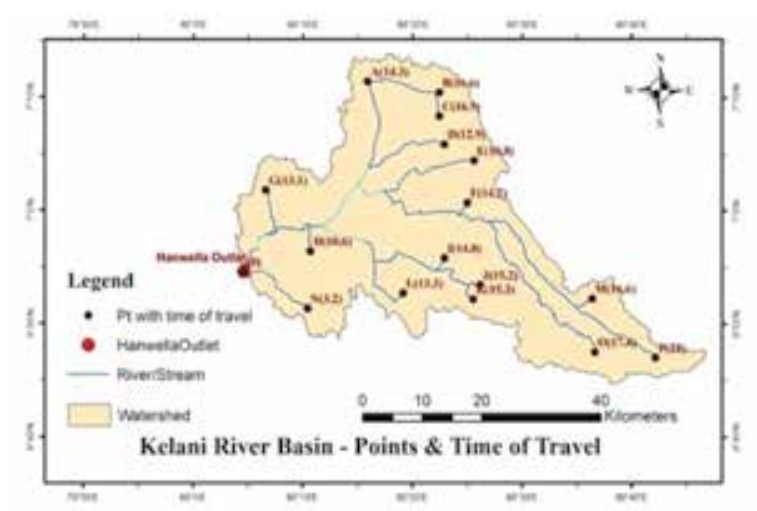

Figure 5-Points Identified Using HEC-GeoHMS and Their Time of Travel

The time of concentration $\left(T_{c}\right)$ is considered as 18 hrs during the computations. Kelani river basin upto Hanwella is divided into 18 different subareas enclosed between the two consecutive isochrones having time of travels $(\Delta \mathrm{tc})$ of 1 hour as shown in Figure 6 . The time of travels associated with each isochrone and the area enclosed between the two consecutive isochrones are computed. Then, the cumulative area and time of travels are also computed. Subsequently, the value of $t / T c$ and At/A are computed.

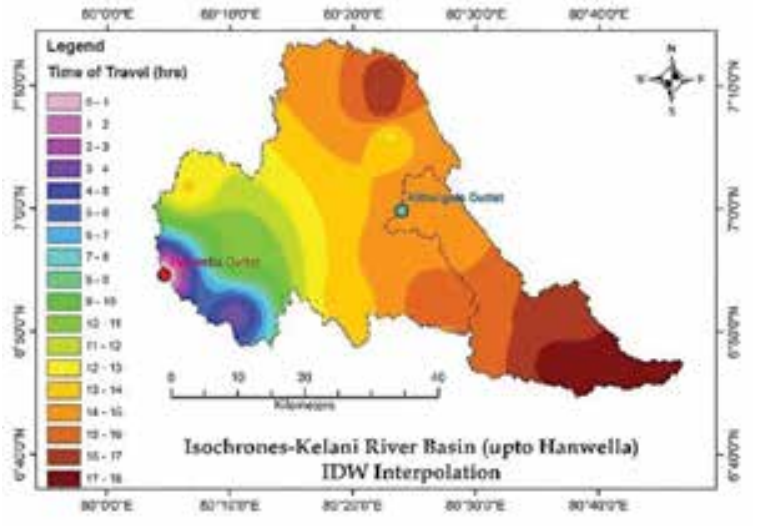

Figure 6 - Isochrones of Kelani River Basin (IDW)

The time-area percent curves using the IDW interpolated isochrones, is developed as shown in Figures 7. The figure represents that first half of the time of concentration is consumed by around $50 \%$ of the basin area and the second half of time of concentration is consumed by the remaining area of the basin from the outlet Hanwella. It means that upper terrain and lower terrain yield equal contribution of flow to the river.

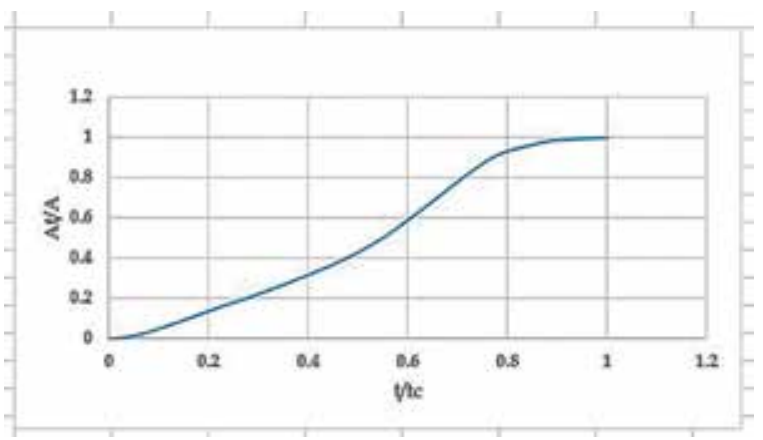

Figure 7 - Time - Area Percent Curve of IDW Interpolation Method

Kriging Interpolation Method (using ArcGIS): Figure 8 shows the isochrones of Kelani river basin developed using the Kriging interpolation technique of ArcGIS. Kelani river basin upto Hanwella is divided into 18 different subareas enclosed between the two consecutive isochrones having a time of travel of one hour. The time of travel associated with each isochrone and the area enclosed between the two consecutive isochrones are computed. Then, the cumulative area and time of travels are computed. Subsequently, the value of $t / T c$ and At/A are computed. These values are used to develop corresponding time area histograms and time area percent curves. 


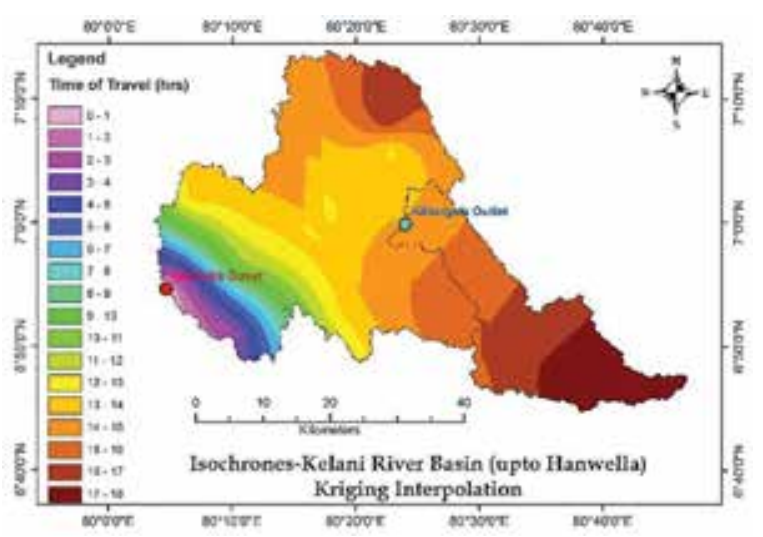

Figure 8 -Isochrones of Kelani River Basin (Kriging)

The time-area percent curves using the 'kriging' interpolated isochrones, are developed as shown in Figure 9. The figure indicates that first half of the time of concentration is consumed by around $15 \%$ of the basin area and the second half of time of concentration is consumed by the remaining area of the basin from the outlet Hanwella. It means that upper terrain yields a predominant contribution of flow compared to lower terrain.

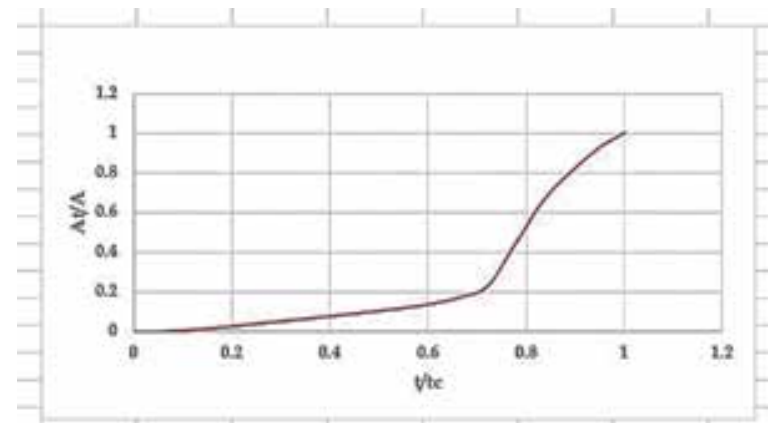

Figure 9 -Time - Area Percent Curve of Kriging Interpolation Method

Synthetic Method: The HEC-HMS software has a predefined typical time-area relationship which has been built into the programme as described under Section 2.2. Time-Area calculations are made using the time area relationship shown in Eq. (4) to develop the time area percent curve. Figures 10 reveals that the time of travels and the relevant isochrones area are well distributed in order to obtain the time - area percent curve considering the diamond shape catchment.

Finally, the time-area percent curves obtained from three different methods are compared as shown in Figure 11. From this figure, it is observed that there is not much variation in the shape of the time-area percent curves developed by both the two interpolation methods.

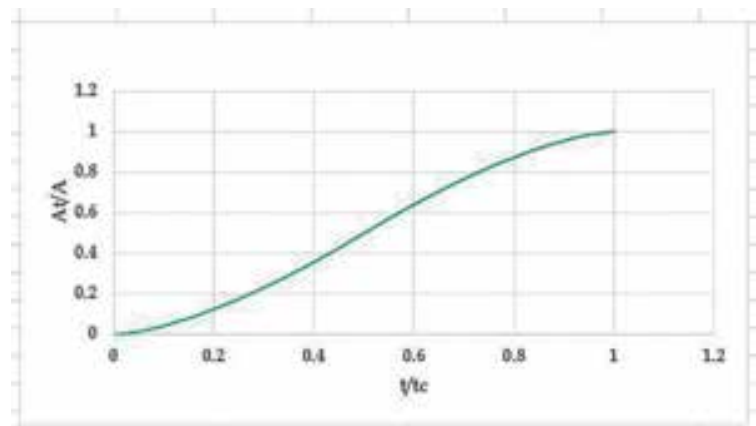

Figure 10 - Time - Area Percent Curve of Synthetic Method

However, the time-area percent curve generated by the synthetic time-area relationship shows considerable deviation compared to the time-area percent curves derived from the two interpolation methods. The time-area relationship obtained from Kriging interpolation method was adopted in the Clark transform model of HEC-HMS.

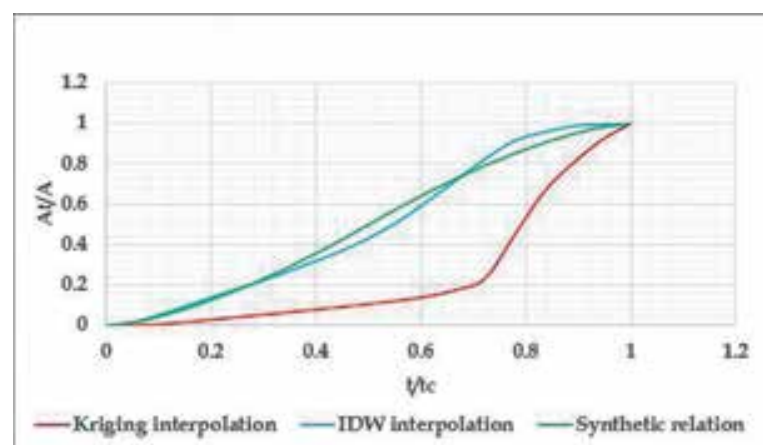

Figure 11 - comparison of Time - Area Percent Curves

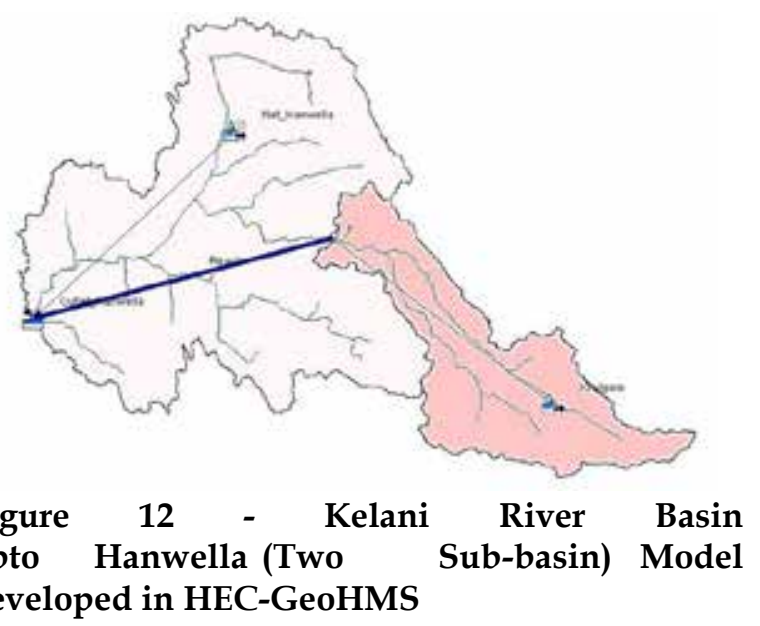

Figure 12 shows the Kelani river basin model up to Hanwella and its hydrologic elements network of both sub basins, developed in HEC-GeoHMS. The area of Hanwella net sub basin is 1359 sq.km whereas the area of Kithulgala sub basin is 472 sq.km. Although both the sub basins have different time -area relationships, a common timearea relation for the entire basin is able to be applied in HEC-HMS. 


\subsection{Computation of Initial Model Parameters}

Barnes (1940) introduced the recession storage of a basin $\mathrm{Q}_{\mathrm{t}}=\mathrm{Q}_{0} \cdot \mathrm{K}_{\mathrm{r}}=\mathrm{Q}_{0} . \mathrm{e}^{-\mathrm{at}}$; where $\mathrm{Q}_{0}$ and $\mathrm{Q}_{\mathrm{t}}$ are discharge at time interval $t$ days with $\mathrm{Q}_{0}$ being the initial discharge. $\mathrm{K}_{\mathrm{r}}$ is the recession constant of value less than unity; $a=\left(-\ln K_{r}\right)$. Figure 13. shows the recession curve obtained from the flood hydrograph of Hanwella gauging station during the event of May 2017. From this curve, the base flow model parameters for the Hanwella net basin are computed. The initial discharge, recession constant and the threshold discharge are computed to be $9.5 \mathrm{~m}^{3} / \mathrm{s}, \quad 0.9$ and $215 \mathrm{~m}^{3} / \mathrm{s}$ respectively. These initial values are also used for the other flood events for their simulations.

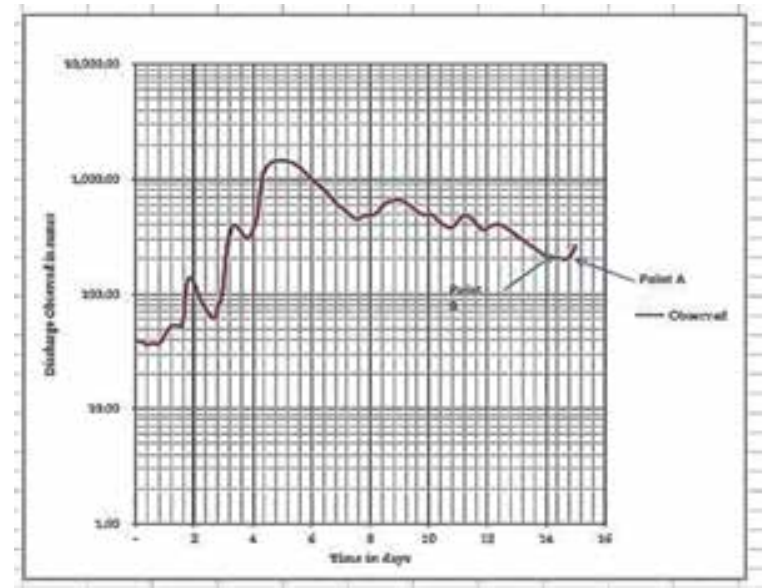

Figure 13-Recession Curve - May 2017 Event

The sensitivity analysis for the three simulations under the Clark UH is carried out as described in Section 2.3. The NSE values for the various sets of Tc and R parameters for Hanwella net basin are found during simulation of the storm event of May 2017 and those NSE values are computed. The computed NSE values, corresponding to a set of Tc and $R$ values, are plotted in Figure 14. and contours for NSE values are drawn in Figure 18. The initial values of parameters $T c$ and $R$ are identified from the highest range of NSE contours. Thus, the initial values of Tc and R, obtained from sensitivity analysis, are considered as $28 \mathrm{hr}$ and $48 \mathrm{hr}$ respectively for computing the optimum values of Tc and R using HEC-HMS for the event of May 2017. Similarly, the initial values of Tc \& R are computed to be $28 \mathrm{hrs} \& 48 \mathrm{hrs}$, and $28 \mathrm{hrs} \&$ 36 hrs for the events 2014 December, and 2012 November respectively, during sensitivity analysis. From Figures 14 \& 15, it is observed that the parameter Tc is more sensitive compared to parameter $\mathrm{R}$ for the Hanwella net basin [15] .

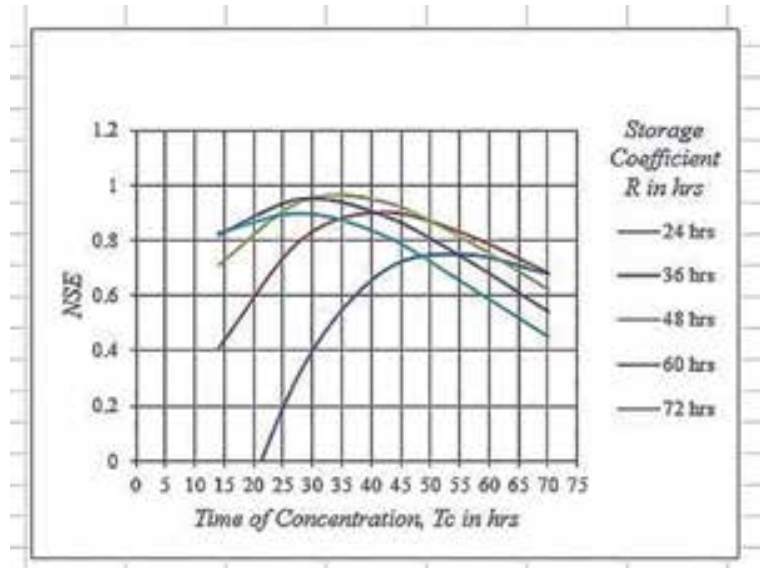

Figure 14 - Variation of NSE with Sensitive Parameters Tc \& R (Hanwella net basin, May 2017)

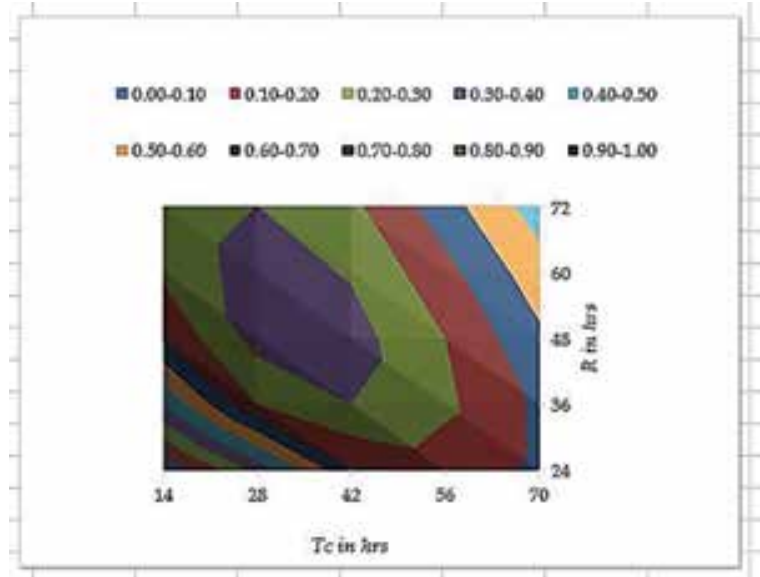

Figure 15 - Contour of NSE with Sensitive Parameters Tc \& R (Hanwella net basin, May 2017)

Subsequently, the sensitivity analysis for the three simulations under the Clark UH for Kithulgala sub basin is carried out. Similar to the Hanwella net basin, the computed NSE values, corresponding to a set of Tc and $\mathrm{R}$ values, are plotted as shown in Figure 16, and contours for NSE values are drawn Figure 17. The initial values of parameters $\mathrm{Tc}$ and $\mathrm{R}$ are identified from the highest range of NSE contours. Thus, the initial values of Tc and R, obtained from sensitivity analysis, are considered as $28 \mathrm{hr}$ and $48 \mathrm{hr}$ respectively for computing the optimum values of Tc and R using HEC-HMS for the event of May 2017.

Similarly, the initial values of Tc \& $\mathrm{R}$ are computed to be $5 \mathrm{hrs} \& 15 \mathrm{hrs}$ and $3 \mathrm{hrs} \& 10 \mathrm{hrs}$ for the events of 2014 December and 2012 November respectively, during sensitivity analysis. From Figures $16 \& 17$, it is observed that the parameter $\mathrm{R}$ is more sensitive compared to parameter $\mathrm{Tc}$ for the Kithulgala subbasin. 
Subsequently, the initial parameter values of lag for the routing process in HEC-HMS are identified through such sensitivity analysis. The lag time for the events of 2017 May, 2014 December and 2012 November are 300 minutes, 300 minutes and 100 minutes respectively.

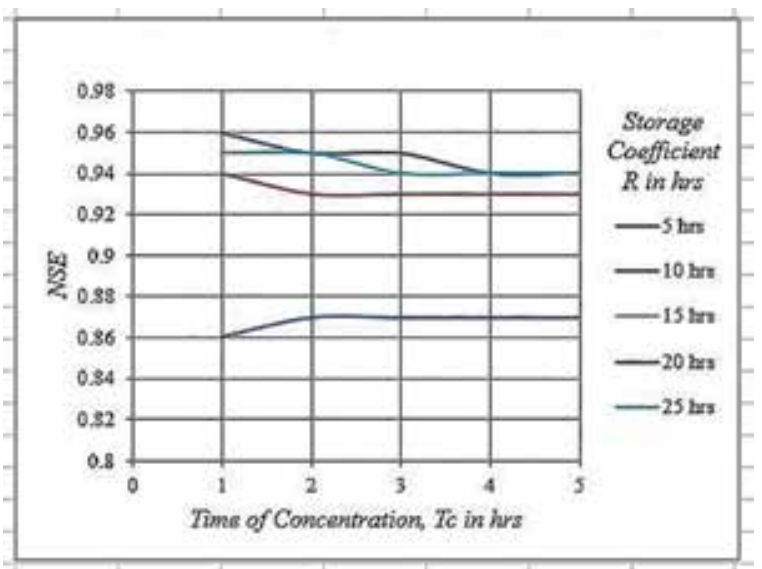

Figure 16 - Variation of NSE with Sensitive Parameters Tc \& R(Kithulgala sub basin, May 2017)

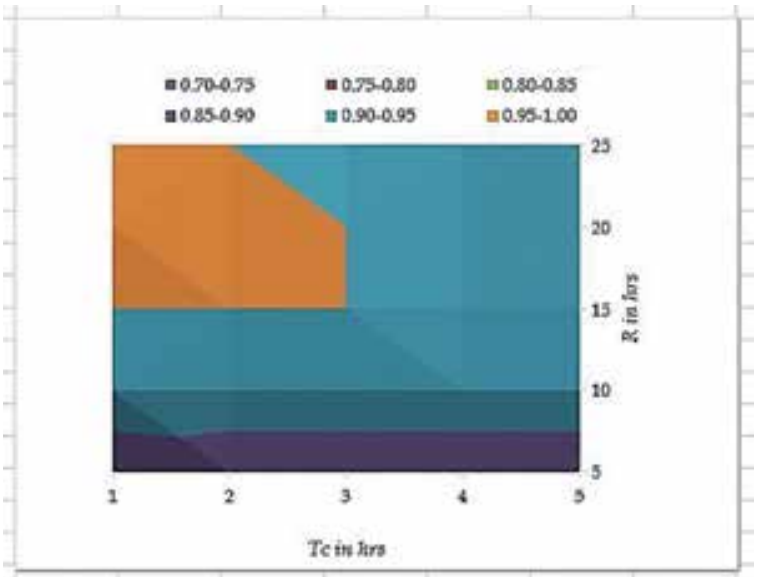

Figure 17 - Contour of NSE with Sensitive Parameters Tc\&R(Kithulgala sub basin,May 2017)

\subsection{Model Calibration and Validation using Three Different Time-Area Relations}

For the calibration of the transform models, data from three extreme events are considered whereas one extreme event data is used for the validation for Kelani river basin. The initial values of hydrological parameters are obtained from the sensitivity analysis of the Clark UH transform model with respect to the time-area percent curve used whereas initial values of the other measured parameters are derived from the spatial data processing.

The simulated flood hydrographs using the optimized parameters from synthetic time-area percent curve application are shown in the Figures 18 (a), (b) and (c) for the three different events. During calibration of the three events, the optimization option available in the simulation manager of HEC-HMS is individually used for the events to optimize the Clark UH model parameters such as Tc and $R$. The initial values of Tc and $R$, which are obtained from the sensitivity analysis, are used. The optimized values of these parameters of the individual events are used to compute the average values, also known as representative values.

The average values of optimized Tc for Hanwella net basin (=27.4 hrs), Tc for Kithulgala sub basin (=1.9 hrs), $\mathrm{R}$ for Kithulgala sub basin (=12.3 hrs) and lag time for reach routing, are nearly the same as their optimized values obtained from the three events whereas the average value of optimized $R$ for Hanwella sub basin (=41.1 hrs) differs from its optimized value of all the event simulations during calibration.

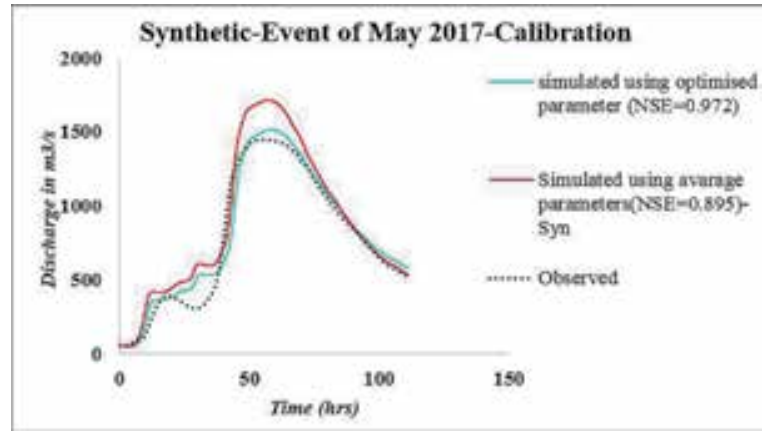

(a)

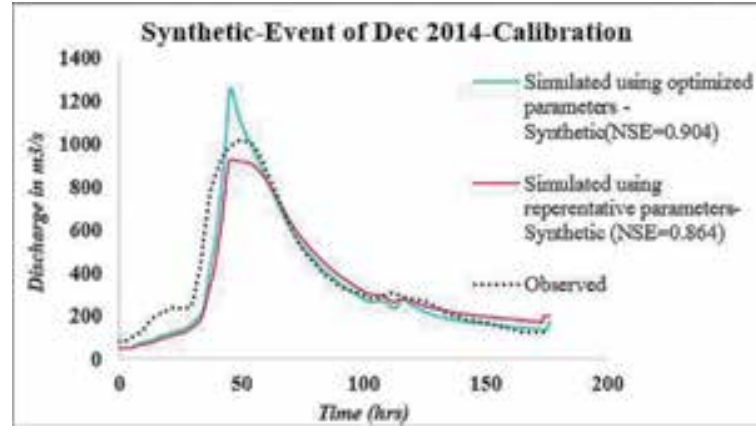

(b)

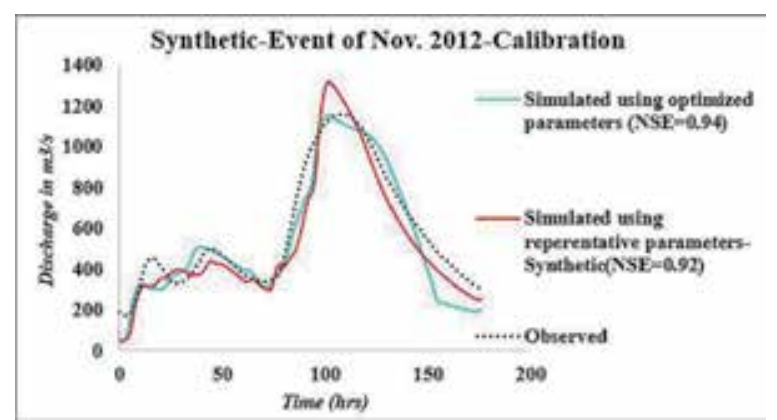

(c)

Figure 18 - Simulations Using Optimized \& Representative Parameters During Calibrations of The Three Events Using Synthetic Time-Area Percent Curves 
Similarly, the simulated flood hydrographs using the optimized parameters from IDW interpolated and 'Kriging' interpolated time-area percent curve application, are shown in Figures 19 (a), (b) \& (c) and Figures 20 (a), (b) \&(c) for the three different events. In both the cases where IDW and 'Kriging' interpolated time-area percent curves are used, the representative parameter values of Tc for both the sub basins are almost similar to its optimized parameter values during calibration of all the events. And the representative value of $\mathrm{R}$ for the Hanwella sub basin differs from its optimized parameter value during calibration of all the events.

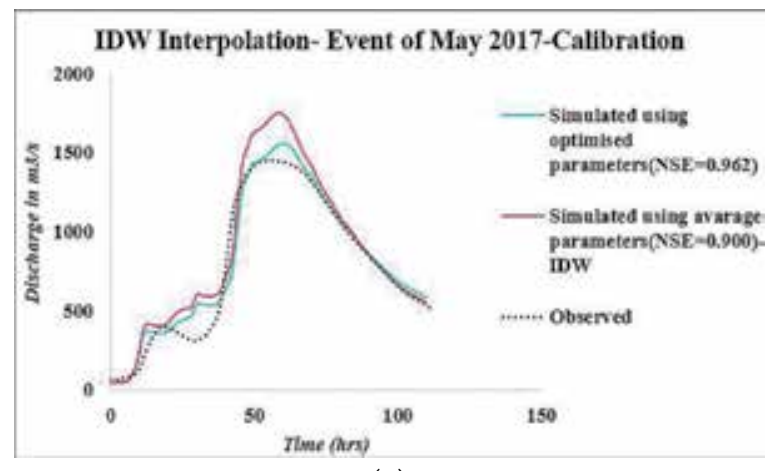

(a)

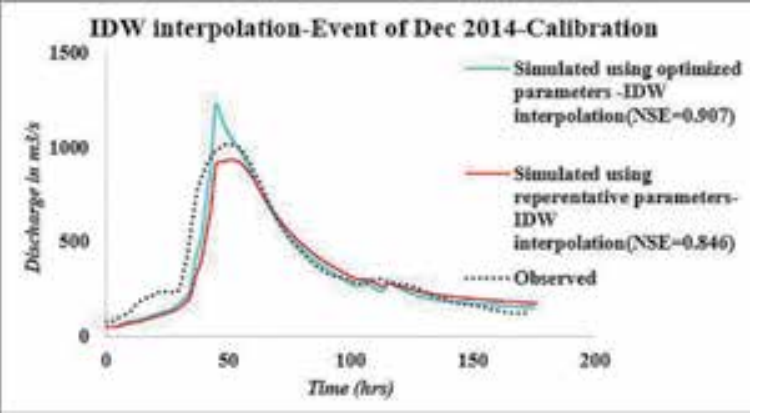

(b)

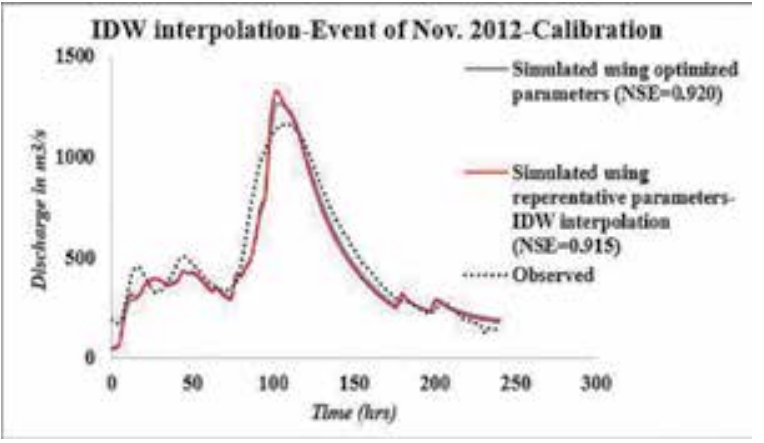

(c)

Figure 19 - Simulations Using Optimized \& Representative Parameters During Calibrations of the Three Events Using IDW Interpolated Time Area Percent Curves

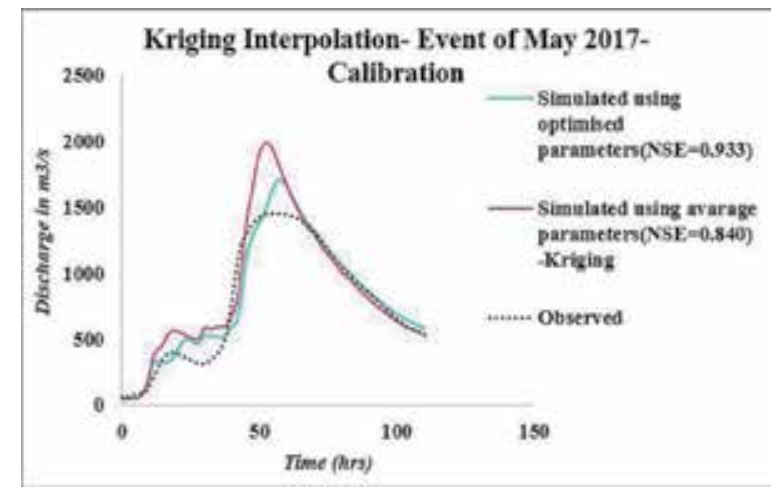

(a)

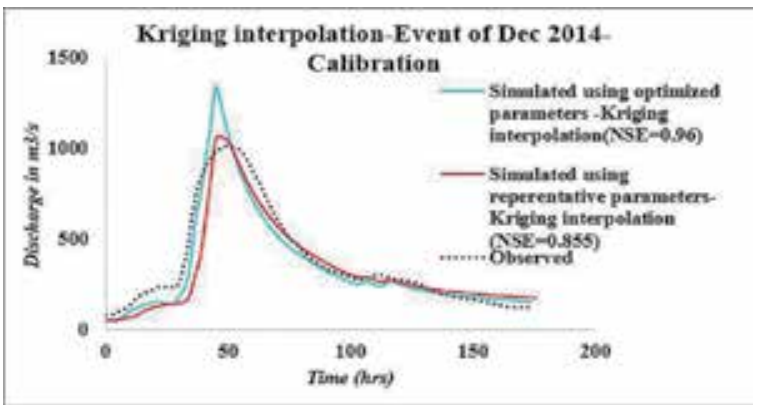

(b)

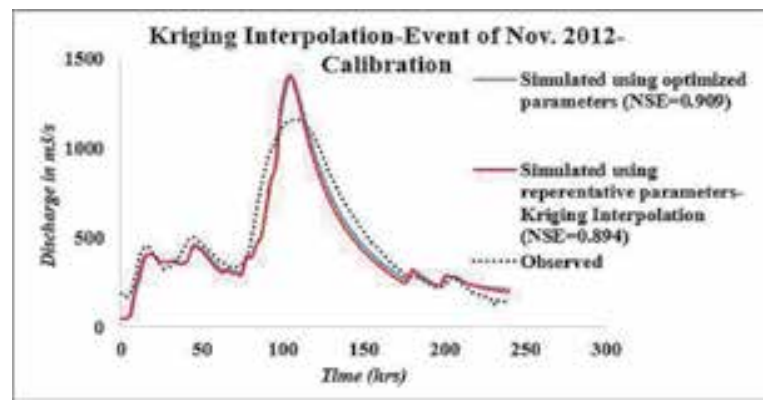

(c)

Figure 20 - Simulations Using Optimized \& Representative Parameters During Calibrations of the Three Events Using 'Kriging' Interpolated Time-Area Percent Curves

\subsection{Comparison of the Performance of Three Different Simulations}

Table 4 represents the representative parameter values(average) computed from the optimized parameters values, which are obtained during calibrations with respect to the application of three different time-area percent curves. The parameter Tc of Hanwella sub basin under Kriging interpolated time-area case gives significantly less hours compared to the other time-area cases. Also, other parameters do not appear to be significantly different for different percent curves. 
Table 2 - Average of Optimized Parameters (Representative Parameters) for the Three Simulations from Calibration

\begin{tabular}{|c|c|c|c|c|c|}
\hline \multirow{2}{*}{ Elements } & \multirow{2}{*}{ Parameters } & \multirow{2}{*}{ Unit } & \multicolumn{3}{|c|}{ Time-Area Relations } \\
\hline & & & Synthetic & $\begin{array}{c}\text { IDW } \\
\text { interpolation }\end{array}$ & $\begin{array}{c}\text { Kriging } \\
\text { interpolation }\end{array}$ \\
\hline $\begin{array}{c}\text { Hanwella_Net } \\
\text { Sub basin }\end{array}$ & $\begin{array}{l}\text { Clark Unit Hydrograph } \\
\text { - Time of Concentration }\end{array}$ & HR & 27.4 & 26.7 & 13.4 \\
\hline $\begin{array}{l}\text { Hanwella_Net } \\
\text { Sub basin }\end{array}$ & $\begin{array}{l}\text { Clark Unit Hydrograph } \\
\text { - Storage Coefficient }\end{array}$ & HR & 41.1 & 42.6 & 46.6 \\
\hline $\begin{array}{l}\text { Kitulgala sub } \\
\text { basin }\end{array}$ & $\begin{array}{l}\text { Clark Unit Hydrograph } \\
\text { - Time of Concentration }\end{array}$ & $\mathrm{HR}$ & 1.9 & 0.9 & 1.0 \\
\hline $\begin{array}{l}\text { Kitulgala sub } \\
\text { basin }\end{array}$ & $\begin{array}{l}\text { Clark Unit Hydrograph } \\
\text { - Storage Coefficient }\end{array}$ & HR & 12.3 & 12.6 & 13.0 \\
\hline Reach & Lag - Lag & MIN & 226.6 & 291.3 & 292.5 \\
\hline
\end{tabular}

Figure 21 shows the comparison of simulated flood hydrographs, using representative parameters of the three time-area percent curves approaches, with the observed flood hydrograph for the event of May 2017 during calibration. Figure 22 shows the comparison of percent errors in peaks, time to peaks and discharge volumes, with the three-different time-area percent curve applications for the May 2017 event.

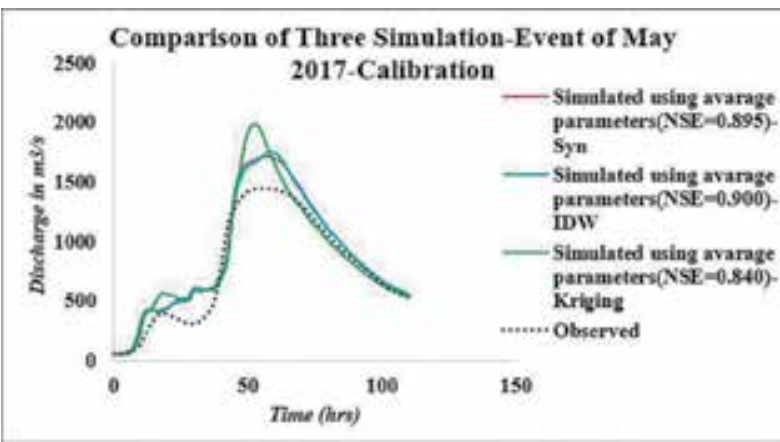

Figure 21 - Simulations using representative parameters of three time-area relations for May 2017 event

From these figures, it is observed that the overall model efficiency NSE values are almost same for the three different cases.

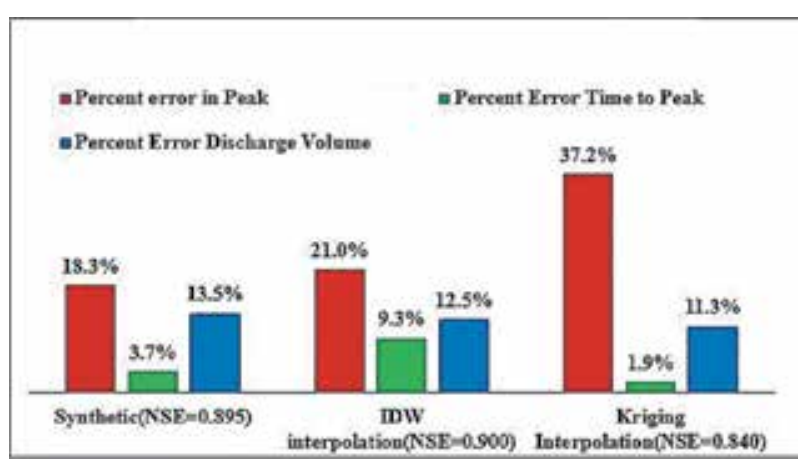

Figure 22 - Percent Errors of Three time-area percent curve approaches during Calibration using Representative Parameters - May 2017
Similarly, Figures 23 \& 25 show the comparison of simulated flood hydrographs using representative parameters of the three time-area percent curve approaches, with the observed flood hydrograph for the events of Dec 2014 and Nov 2012 respectively, during calibration. Figures $24 \& 26$ show the comparison of percent errors in peaks, time to peaks and discharge volumes, with the three-different time-area percent curve applications for the events Dec 2014 and Nov 2012 From these figures, it is observed that the overall model efficiency NSE values are almost same for the three different cases.

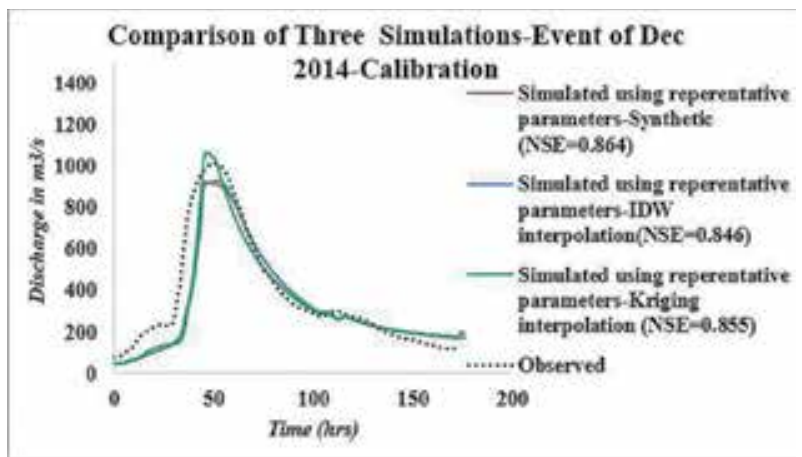

Figure 23 - Simulations using representative parameters of three time-area relations for Dec 2014 event

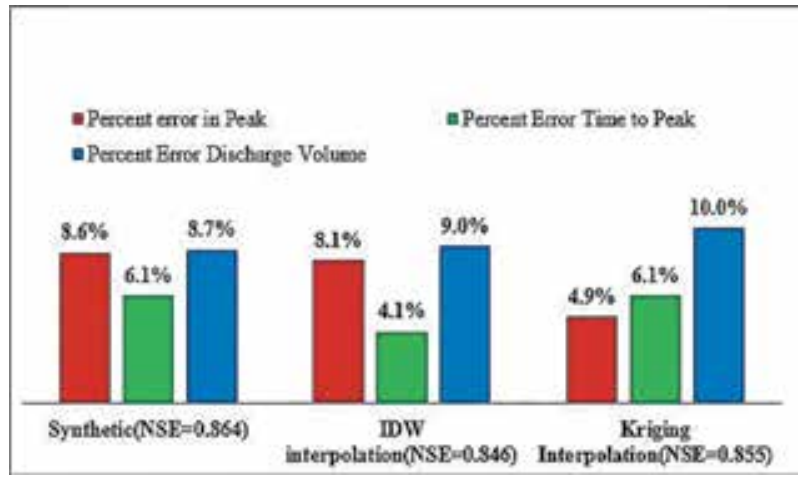

Figure 24 - Percent Errors of Three time-area percent curve approaches during Calibration using Representative Parameters - Dec 2014. 


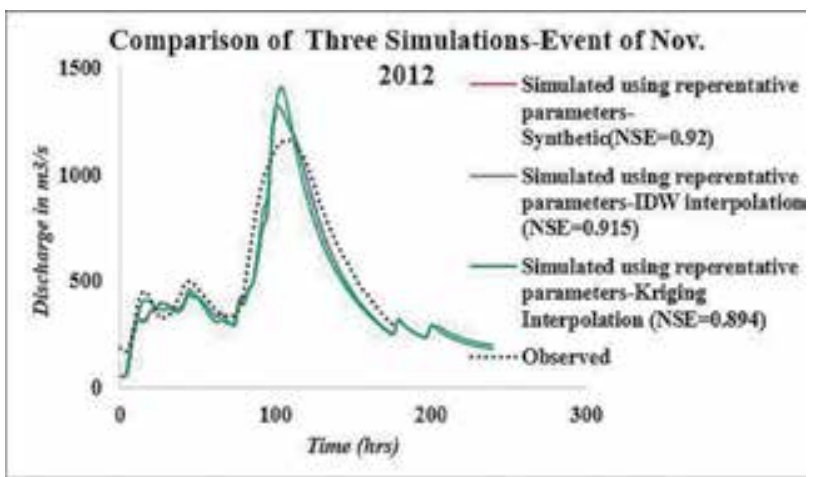

Figure 25 - Simulations using representative parameters of three time-area relations for Nov 2012 event

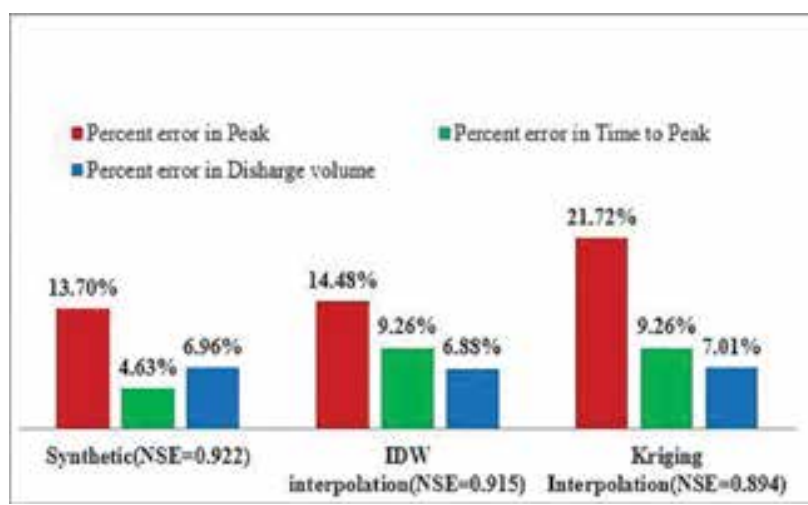

Figure 26 - Percent Errors of Three time-area percent curve approaches during Calibration using Representative Parameters - Nov 2012

Figure 27 shows the comparison of simulated flood hydrographs using representative parameters of the three time-area percent curve approaches, with the observed flood hydrograph for the event of Jun 2014 during validation. Figure 28 shows the comparison of percent errors in peaks, time to peaks and discharge volumes, with the three-different time-area percent curve applications for the Jun 2014 event. From these figures, it is observed that the overall model efficiency NSE value of Kriging interpolation case is quite higher than that of other two time-area percent curve cases.

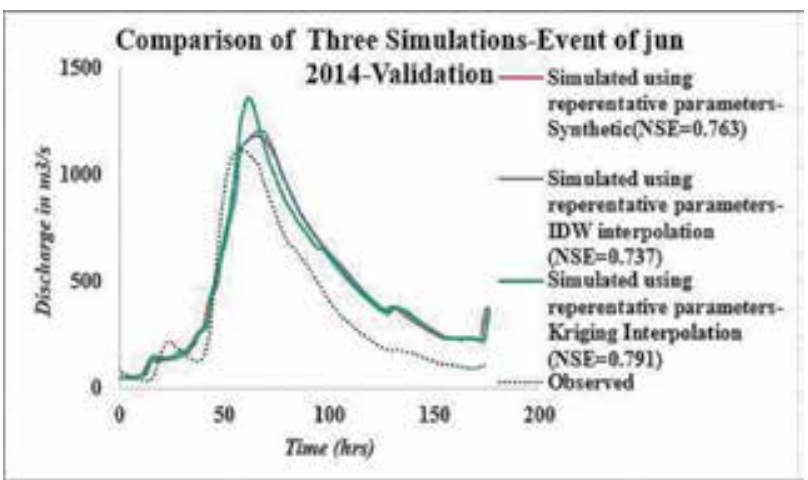

Figure 27 - Simulations using representative parameters of three time-area relations for Jun 2014 event

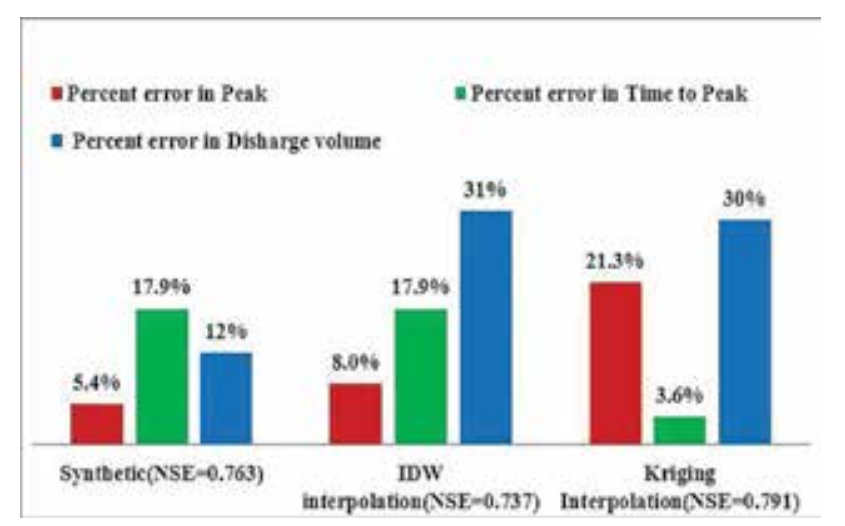

Figure 28 - Percent Errors of Three time-area percent curve approaches during Validation using Representative Parameters - Jun 2014

Table 5 shows the NSE values resulted during the calibration and validation of Clark UH model using three time-area percent curves. Calibration of the three events yields a comparatively higher value for the synthetic time-area percent curve approach whereas validation of the single event results in a comparatively higher value for Kriging interpolated time-area percent curve case.

Table 3 - Nash-Sutcliffe Model Efficiency (NSE) values obtained from Calibration and Validation using Representative Parameters

\begin{tabular}{ccccc}
\hline \multirow{2}{*}{ Computation } & \multirow{2}{*}{ Event } & \multicolumn{3}{c}{ Time-Area Relations } \\
\cline { 3 - 5 } & & Synthetic & IDW interpolation & Kriging Interpolation \\
\hline \multirow{2}{*}{ Calibration } & 2017 May & 0.895 & 0.900 & 0.840 \\
& 2014 Dec. & 0.864 & 0.846 & 0.855 \\
& 2012 Nov. & 0.922 & 0.915 & 0.894 \\
\hline Validation & 2014 Jun. & 0.763 & 0.737 & 0.791 \\
\hline
\end{tabular}




\section{Conclusions}

Only three of recent past flood events have been used for calibration and one event has been used for validation. However, the validation of the event of June 2014 yields a comparatively higher NSE value for the 'kriging' interpolated time-area percent curve method. Also, the more sensitive parameter Tc $(=13.4 \mathrm{hrs})$ of the Hanwella sub basin significantly differs from the Tc of other cases. Tc is the one of the principal hydrograph properties of Clark UH. Hence, the kriging interpolated time-area percent curve is very much applicable in the use of Clark UH model of HECHMS compared to other types of time-area percent curves.

The area of Hanwella subbasin and Kithulgala sub basin are 1359 sq.km and 472 sq. km respectively. If the application of the time-area percent curves is used in large watershed areas, the NSE values on each time-area percent curve approaches may significantly vary from each other.

\section{Acknowledgements}

The authors would like to acknowledge the opportunities provided by the Institute of Engineers, Sri Lanka, to publish this paper in the journal ENGINEER of that institution, in the year 2019. The authors also thank to the Department of Irrigation, Sri Lanka for providing the required data for the study.

\section{References}

1. USACE-HEC, Hydrologic Modelling System HEC-HMS , Application Guide, USACE, Hyd. California,USA: Davis, 2015.

2. Clark, C. O., "Storage and the Unit Hydrograph," Am. Soc. Civ. Eng., vol. Vol. 110, no. 1, pp. 1419-1446, 1945.

3. Singh, P. K., Mishra, S. K., and Jain, M. K., “A Review of the Synthetic unit Hydrograph: from the Empirical UH to Advanced Geomorphological Methods," Hydrol. Sci. J., vol. 59, no. 2, pp. 239-261, 2014.

4. Kumar, R., Chatterjee, C., Singh, R. D., Lohani, A. K., and Kumar, S., "GIUH Based Clark and Nash Models for Runoff Estimation for an Ungauged Basin and their Uncertainty Analysis," Int. J. River Basin Manag., vol. 2, no. 4, pp. 281-290, 2004.
5. Ahmad, M. M., Ghumman, A. R., and Ahmad, S., "Estimation of Clark's Instantaneous Unit Hydrograph Parameters and Development of Direct Surface Runoff Hydrograph," Water Resour. Manag., vol. 23, no. 12, pp. 2417-2435, 2009.

6. Lohani1, A. K., and Sanjay Kumar1 Rakesh Kumar, 1 C. Chatterjee, 2* R. D. Singh, "Runoff Estimation for an Ungauged Catchment using Geomorphological Instantaneous Unit Hydrograph (GIUH) models," Hydrol. Process., vol. 21, pp. 1829-1840, 2007.

7. Sivakumaran Rajkumar; SK Mishra; RD Singh, "Application of Hydrologic Modelling System (HEC-HMS) for Flood Assessment; Case Study of Kelani River Basin, Sri Lanka.,"Conference paper (accepted)" -Sustainable Tecnologies for Inteligent Water Management(STIWM-2018).

8. Sampath, D. S., Weerakoon, S. B., and Herath, S., "HEC-HMS Model for Runoff Simulation in A Tropical Catchment with Intra-Basin Versions: Case Study of the Deduru Oya River Basin, Sri Lanka," Engineer, vol. XLVIII, no. 01, pp. 1-9, 2015.

9. Nandalal, H. K., and Ratnayake, U. R., “Event Based Modeling of a Watershed Using HECHMS," vol. XXXXIII, no. 02, 2010.

10. Jain, S. K., Singh, R. D., and Seth, S. M., “Design Flood Estimation using GIS Supported GIUH Approach," Water Resour. Manag., vol. 14, no. 5, pp. 369-376, 2000.

11. Razi, M. A. M., Ariffin, J., Arish,N. A. M, “Flood Esimation Studies using Hydrlogical Modelling System (HEC-HMS) for Johor River , Malaysia," J. Appl. Sci., vol. 10, pp. 930-939, 2010.

12. USACE-HEC, Geospatial Hydrologic Modelling Extension HEC-GeoHMS, Version 10.1, User's Manual. California,USA: Davis, 2013.

13. McCuen, R. H., Knight, Z., and Cutter, A. G., "Evaluation of the Nash-Sutcliffe Efficiency Index," J. Hydrol. Eng., vol. 11, no. 6, pp. 597$602,2006$.

14. USACE-HEC, Hydrologic Modelling System HEC-HMS, Version 4.2, User's Manual. California,USA: Davis, 2016. 